\title{
A Proposed Invention in Science Labs (ISL) \\ Framework for Teaching Science
}

\author{
Mustafa Jwaifell (Corresponding author) \\ Associate professor in Department of Curriculum and Instruction, Faculty of \\ Educational Sciences, Al-Hussein Bin Talal University \\ PO box 20, Ma'an, Hashemite Kingdom of Jordan \\ Tel: 9-626-775-620480 E-mail: jwaifell@ahu.edu.jo
}

Osama M. Kraishan

Associate professor in Department of Curriculum and Instruction, Faculty of Educational Sciences, Al-Hussein Bin Talal University

PO box 20, Ma'an, Hashemite Kingdom of Jordan

Received: October 21, 2019 Accepted: November 4, 2019 Online Published: November 15, 2019

doi:10.5296/ijld.v9i4.15658ＵRL: https://doi.org/10.5296/ijld.v9i4.15658

\begin{abstract}
The proposed Invention in Science Labs (ISL) framework conceptualizes invention within science labs through four elements representing phases of reaching inventions in a group context: Theoretical thinking: fluency, flexibility, and originality, solution, materials and context. Four phases should lead to a product that can be commercialized, while the whole process monitored through four procedures under the teacher's supervising the activities: Objectives, Procedures, Discussion, and Evaluation. The study listed the challenges faced during the implementation of ISL which can be overcome if policy makers have the awareness of using ISL in teaching, while teachers can change their approaches of instruction when they have the opportunity to practice it. Besides, the Jordanian Ministry of Education in general can conduct contests between students and schools to have more inventions which encourages using ISL framework. The study also proposed appropriate solutions for overcoming those challenges.
\end{abstract}

Keywords: Physics, science labs, creativity, invention, innovation 


\section{Macrothink Institute ${ }^{T M}$}

\section{Introduction}

Little attention has been given to inventing under the umbrella of education as explained in a study conducted by Jwaifell and Kraishan (2019) to investigate elementary students' invention ingenuity in science labs and test the ISL framework. The study participants were (50) male and female ninth-grade students. The study used mixed approaches of both qualitative and quantitative methodologies to assure the effectiveness of the ISL framework. The results were very promising for the use of ISL. This paper describes how the ISL works and what it is consisted of, in addition to the challenges that might be faced during the process of implementation.

\section{Background}

Most of researches conducted under the claim of students' acquiring epistemology of disciplines through teaching by creativity without transforming the theoretical ideas into products that can be commercialized, which is the main ISL concern. While researchers tried to develop and implement creativity in the form of invention. Bostrom and Nagasundaram (1998) provided suggestions for future research in creativity factors, where they classify their work in terms of whether it addresses the creative Person, Product and Press as adapted from Fellers and Bostrom (1993):

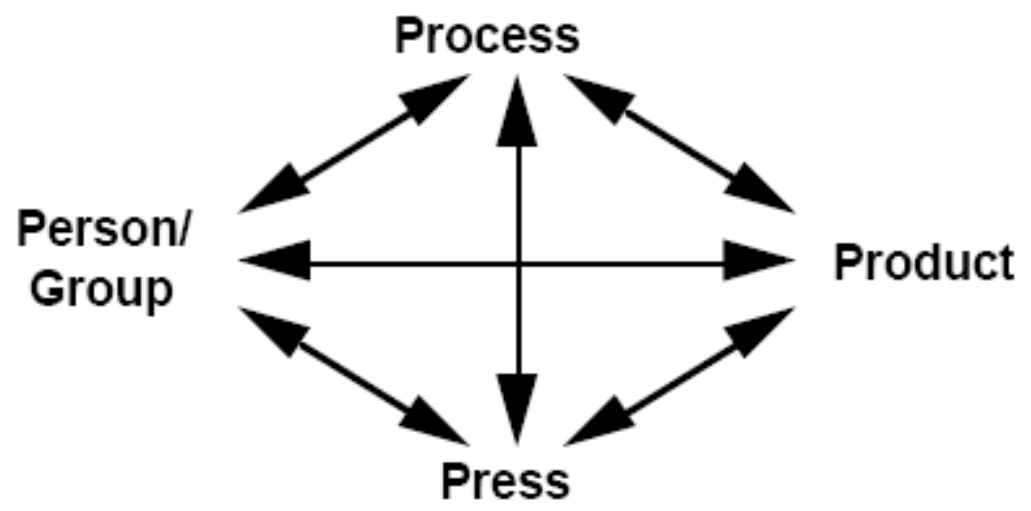

Figure 1. Creativity factors (Bostrom \& Nagasundaram, 1998, p391)

Other scholars framed teaching and learning innovation and invention. Schull, Maytychak, and Noel-Storr (2009) described the practices they used in their course on Innovation and Invention which had been taught at Rochester Institute of Technology as Figure 2 describe: 


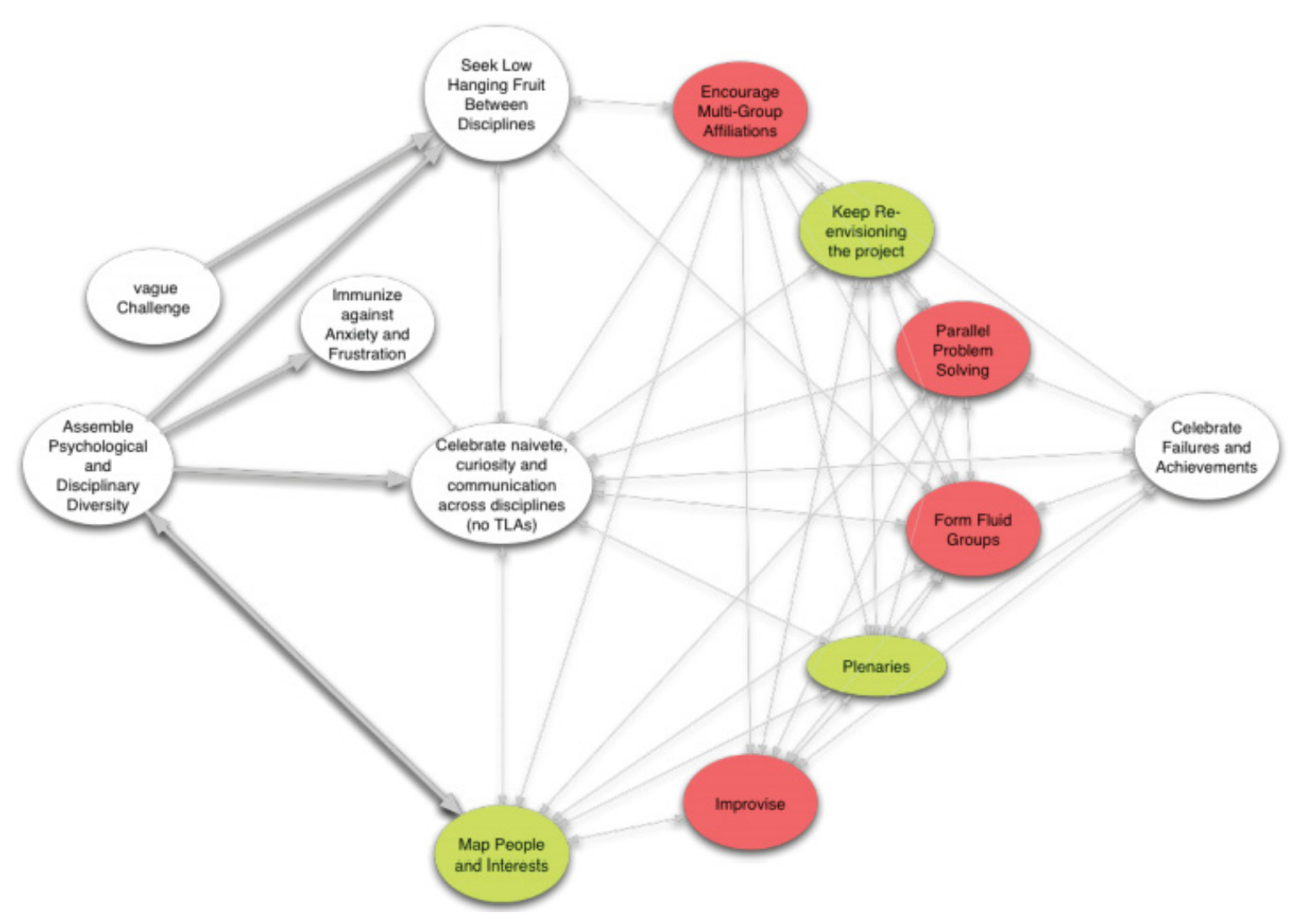

Figure 2. Key practice of a course on Innovation \& Invention (Schull et al, 2009. 4)

A framework suggested by Meyer and Lederman (2013) to explore the pedagogy of ingenuity in science classrooms as a guide to analysis of each of the activities the teachers shared on the questionnaire and observed by the researchers. This facilitates the researchers' assessment of whether each activity had the potential to permit fluency, flexibility, and thus potential for responses that are significantly different across a group of students (original) as shown in Figure3: 


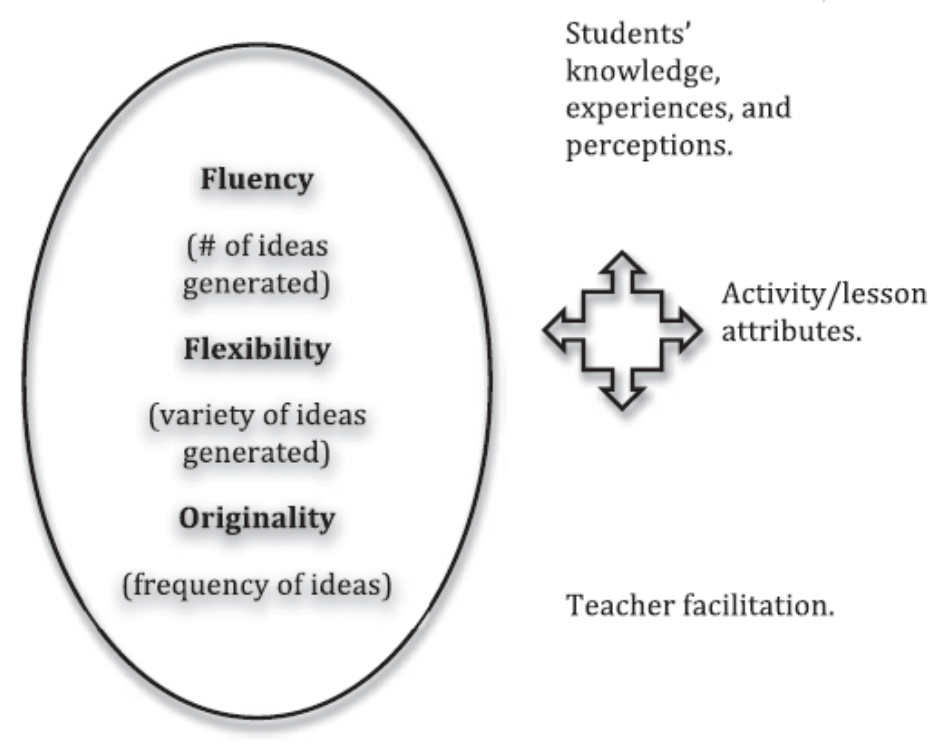

Figure 3. Creative thinking in the science classroom analysis framework (Meyer \& Lederman, 2013, p403)

\section{ISL Framework}

The proposed ISL framework was designed and developed through a pre-experimental research conducted by Jwaifell and Kraishan (2018) where its instruments validity and reliability were assured. The research was teamwork achievement developed by two male $\backslash$ female teachers and the two researchers. The role of the two teachers was concerned with applying ISL, while the researchers analyzed the literature related to teaching strategies and methodologies with respect to constructivism theory and creativity approaches in teaching. Figure 4 showing the ISL framework: 


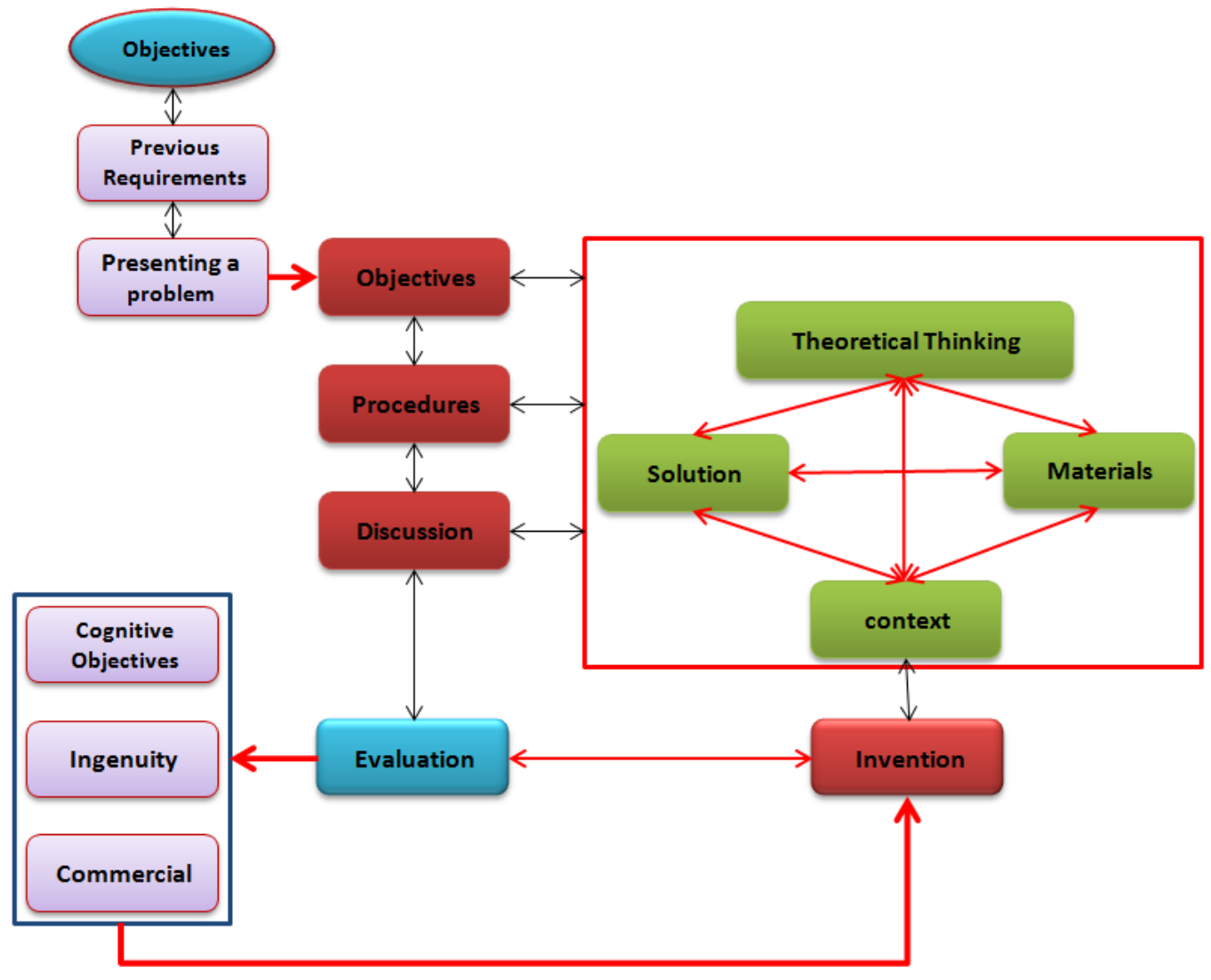

Figure 4. ISL Framework

Teachers with respect to ISL design and plan learninglteaching situations through the following phases:

\subsection{Phase 1: Stating Objectives}

Stating Objectives begins with the common goals that will be achieved by students and understanding the environment where the process of invention will be conducted; which for this study is science laboratories at the school. This phase aims at exploring materials, equipment and media availability, so that outcomes can be reached according to this availability.

The objectives cover cognitive, affective, and psychomotor domains of the subject of the study. While teachers should assure the previous requirements, the study sample of students should possess to accomplish the outcomes, it will be essential to choose the suitable problem that is relevant to exploring materials, equipment and media availability that should be solved by an invention.

For example:

- Objective: connecting a simple electrical circuit.

- Materials etc: welding device, wires, lump, battery ...etc. 


\section{Macrothink}

- Presenting a problem: a doorbell for a deaf person.

- ISL design and plan learninglteaching situations its phases.

\subsection{Phase 2: Procedures}

Dividing students into groups and assigning tasks for each individual of the team. The teacher in this phase revises students' previous knowledge and shapes it by giving scaffoldings for students' acquisition of the subject matter objectives.

\subsection{Phase 3: Discussion}

Discussion phase conducted through all learninglteaching situations. Teachers will discuss all relevant needs to understand the task devoted for the outcome of that should be accomplish by the students. Teachers will change their moves within ISL approach to facilitate learning and explore students' way of thinking for reaching the best solution of the problem presented to each team.

The students will gain subject matter through thinking theoretically $\mathrm{f}$ the problem and what solutions they may come up with based on the knowledge they need to understand regarding the relationship between what they are going to solve and the concepts they have to understand. Theoretical thinking will also include solutions for the problem that should be discussed with the teacher and other students through brain storming and the elimination of improper solutions. The context of applying those solutions as a product will be supervised by the teacher with the relation of the product evaluation card. Here's an example of a problem that needs a solution:

- Problem: Help a blind/deaf person know if someone is at the door of his home?

- Tools/Materials available: Electrical kill key, Electrical lamp, Remote control toy car, Wristwatch, Bill hanged inside a room.

- Describe the above tools and materials functions

- Discuss the relationship between these tools?

- What is the relationship between these tools and the addressed problem?

- Can those tools be helpful to solve the problem?

- Address solutions to help the blind/deaf person by using these tools and materials?

- What is the most suitable solution?

- What are the implementation procedures?

- Suggest how this product can be developed?

- Suggest how this product can be developed commercially?

\subsection{Phase 4: Invention}

The whole team will use every skill they have according to each individual of the team to develop the solution they proposed into a product that works properly according to the 


\section{Macrothink}

evaluation card.

\subsection{Phase 5: Evaluation}

The evaluation phase will measure students' achievements of the subject matter they have learned and evaluate the product they have invented by an evaluation card which contains the following standards:

Table 1. Product Evolution Card

\begin{tabular}{l}
\hline Invention Ingenuity \\
\hline Consistency with religion \\
Applicability \\
Novelty \\
Community needs \\
Efficiency \\
Power saving \\
Easiness of use \\
Cost of materials \\
Safety \\
\hline Total (cut Score $=63)$ \\
\hline
\end{tabular}

The production card consisted of 9 items: Safety, Cost of Materials, Easiness of use, Power saving, Efficiency, Community needs, Novelty, Applicability, and consistency with religion hence people do not change the perceived connection between religion and science, even if they were in a science course which integrated activities explicitly addressing the nature of science (Aflalo, 2018).

\section{Challenges of ISL Implementation}

The implementation of the proposed ISL may be obstructed by some challenges as explained in the study of Jwaifell and Kraishan (2018). One of The biggest challenges that the researchers faced in the pre-experimental study was the cost of materials that students needed to complete the product. Over all challenges can be summarized in four categories:

1. Cost: the previous study of Jwaifell and Kraishan (2018) showed that the cost of each product reached an in average of (52 US\$) which is considered as expensive in a poor country like Jordan. To overcome these kinds of challenges it would be very helpful if the materials used can be reused again in different situations. 


\section{Macrothink Institute ${ }^{\text {TM }}$}

2. Teachers' readiness: teachers understand very well the new methodologies of teaching, but at the same time they need more training in dealing with ISL and the equipments needed for its implementation. This challenge can be overcome through more training courses and virtual courses will be least costly. While teachers' readiness for new methodologies and integrating technologies are high Jwaifell, Abu-Omar, \& Al-Tarawneh (2018).

3. Policy makers' awareness: in countries such as Jordan, policy makers can really make a difference and assure changes if they were aware of the outcomes and benefits of using ISL as learning and teaching framework which lead to quality assurance. This challenge can be overcome by media and community pressure.

\section{Conclusion}

Challenges can be overcome if policy makers are aware of using ISL in teaching, also teachers can change their approaches of instruction when they have the opportunity to practice ISL, and students can be more active and enjoy the learning process. Besides, the Jordanian Ministry of Education can conduct contests between students and schools to enhance inventing and encourage using ISL frameworks.

\section{References}

Aflalo, E. (2018). Changing in perceptions of the nature of science and religious belief. Issues in Educational Research, 28(2), 237-253.

Bostrom, R. P., \& Nagasasundarman, M. (1998). Research in creativity and GSS. Proceedings of the thirty-First Annual Hawaii International Conference on System Sciences. Retrieved April 28, 2017, from https://www.computer.org/csdl/proceedings/hicss/1998/8248/06/82480391.pdf

Jwaifell, M., Abu-Omar, A., \& Al-Tarawneh, M. (2018). The Readiness of Arabic Language Teachers for Integrating Flipped Classroom: Case of Ma'an. International Journal of Instruction, 11(4), 855-868. https://doi.org/10.12973/iji.2018.11454a

Jwaifell, M., Al-Shalabi, H., Andraws, S., Awajan, A., \& Alrabea, A. (2013). The intensity of social networks group use among the students of Jordanian universities. Global Journal of Computer Science and Technology Network, Web \& Security, 13(2), 1-8.

Jwaifell, M., \& Kraishan, O. (2019). Exploring Elementary Students' Invention Ingenuity in Science Labs. Elementary Education Online, 18(2). Retrieved from http://ilkogretim-online.org.tr/index.php/io/article/view/2917

Meyer, A. A., \& Lederman, N. G. (2013). Inventing creativity: An exploration of the pedagogy of ingenuity in science classrooms. School Science and Mathematics, 113(8), 400-409. https://doi.org/10.1111/ssm.12039

Schull, J., Matychak, X., \& Noel-Storr, J. (2009). Teaching and learning innovation and invention. Retrieved from http://scholarworks.rit.edu/other/684 


\section{Macrothink}

International Journal of Learning and Development

ISSN 2164-4063 2019, Vol. 9, No. 4

\section{Copyright Disclaimer}

Copyright for this article is retained by the author(s), with first publication rights granted to the journal.

This is an open-access article distributed under the terms and conditions of the Creative Commons Attribution license (http://creativecommons.org/licenses/by/4.0/). 